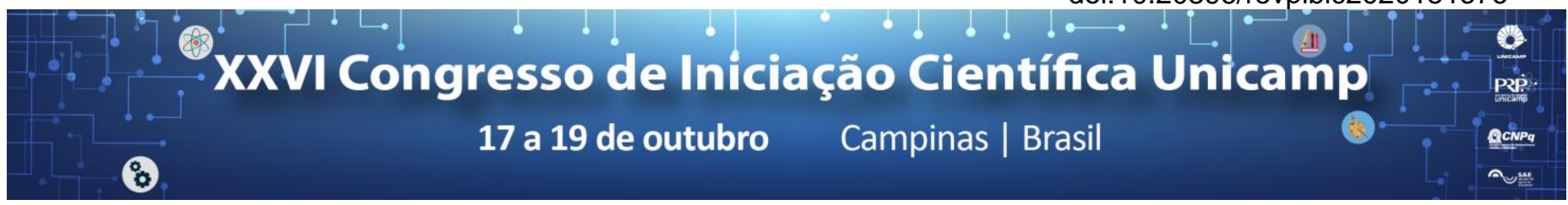

\title{
Avaliação Radiográfica e da Função Musculoesquelética de Pacientes Hemofílicos
}

\section{Vitorugo Silvestre Nascimento*, Bruno Bernardo, Janaina Ricciardi, Margareth C. Ozelo, Rodrigo G. Pagnano}

\section{Resumo}

Esse estudo foi feito com o intuito de avaliar a correlação entre as alterações radiológicas e a clínica de portadores de artropatia hemofílica crônica. No total foram avaliados 49 pacientes através do escore radiográfico de Pettersson e da avaliação de saúde articular (HJHS) e houve boa correlação entre os valores totais de ambos os escores e correlação entre moderada e boa quando as articulações foram avaliadas separadamente.

\section{Palavras-chave: \\ Hemofilia, Artropatia, Classificações Radiográficas.}

\section{Introdução}

A Hemofilia é o distúrbio de coagulação sanguínea mais comum (1). A manifestação mais incapacitante da hemofilia é a hemartrose, uma vez que hemartroses de repeticão podem evoluir para uma sinovite crônica que predispõe a novos sangramentos. Esse quadro por sua vez evolui para a Artropatia Hemofília Crônica (AHC) que, clinicamente, apresenta-se como artralgia, deformidade, limitação de movimentos e atrofia muscular, notadamente em cotovelos, joelhos e tornozelos $(1,2)$. Nesse contexto, alguns sistemas de avaliação baseados em achados clínicos e radiográficos foram criados, como o Escore Radiográfico de Pettersson e o Escore de Saúde Articular em Hemofílicos (HJHS), esse último, composto de 11 itens que permitem avaliar a deterioração articular de forma mais precoce (2, 4). Entretanto, existe uma dissociação clínico-radiológica, ou seja, apesar de um quadro radiológico grave, o paciente pode manter uma amplitude de movimento e função articular razoáveis. Além disso, escalas radiográficas não refletem o impacto dessas alterações no indivíduo de forma global (3). Dessa forma, é importante determinar como essas ferramentas de avaliação se correlacionam entre si, para otimizar a terapêutica da AHC.

\section{Resultados e Discussão}

$\mathrm{Na}$ Tabela 1, temos os valores obtidos nas avaliações para cotovelos $(\mathrm{C})$, joelhos $(\mathrm{J})$ e tornozelos $(\mathrm{T})$, bilateralmente, nos escores de Pettersson e HJHS. No total foram avaliadas 49 pacientes, totalizando 294 articulações. A análise estatística foi feita utilizando a correlação de postos de Spearman, um método não paramétrico em que a correlação é considerada pobre se $r_{s}<0,4$; moderada se $r_{s} 0,4-0,6$; boa se RS 0,6-0,8 e excelente se $r_{s}>0,8$. Os resultados obtidos para rs estão descritos na Tabela 2. A avaliação HJHS apresentou uma boa correlação com o escore de Petterson ( $r_{s}=$ 0,78 ), contudo quando avaliamos as articulações separadamente observamos que a correlação foi moderada entre as avaliações obtidas para cotovelo esquerdo (CE), joelho direito (JD) e tornozelo direito (TD), com rs igual a 0,59; 0,52 e 0,53; respectivamente. Todas as articulações avaliadas, assim como os valores totais dos escores obtidos apresentaram uma correlação estatisticamente significante $(p<0,01)$.

No estudo, os escores de Pettersson e HJHS foram considerados dentro de um intervalo de \pm 6 meses, uma vez que intervalos maiores de tempo podem interferir na correlação devido à maior possibilidade de sangramentos intra-articulares que alterem os escores obtidos.

Tabela 1. Tabela 1. Valores obtidos nas avaliações de Pettersson e HJHS em ombros, joelhos e cotovelos avaliados bilateralmente em 49 pacientes.

\begin{tabular}{lccc} 
& $\begin{array}{c}\mathrm{C} \\
(n=98)\end{array}$ & $\begin{array}{c}\mathrm{J} \\
(n=98)\end{array}$ & $\begin{array}{c}\mathrm{T} \\
(n=98)\end{array}$ \\
\hline $\begin{array}{l}\text { Pettersson (0- } \\
\text { 13) }\end{array}$ & & & \\
0 & 69 & 60 & 59 \\
1 a 3 & 9 & 10 & 13 \\
4 a 7 & 7 & 5 & 11 \\
8 a 13 & 13 & 23 & 15 \\
HJHS (0-20) & & & \\
0 & 31 & 34 & 22 \\
1 а 2 & 23 & 21 & 24 \\
3 a 5 & 15 & 8 & 20 \\
6 a 9 & 11 & 8 & 22 \\
>9 & 18 & 27 & 10 \\
\hline
\end{tabular}

Tabela 2. Análises estatísticas obtidas pelo coeficiente de correlação de Spearman.

\begin{tabular}{lllllll}
\hline & CE & CD & JE & JD & TE & TD \\
\hline$r_{s}$ & 0,59 & 0,64 & 0,77 & 0,52 & 0,67 & 0,53
\end{tabular}

Nos pacientes avaliados houve boa correlação entre os valores totais dos escores radiográficos e de saúde articular, diferentemente da literatura que descreve uma dissociação clínico-radiológica entre os pacientes com artropatia hemofílica.

\section{Agradecimentos}

Conselho Nacional de Desenvolvimento Científico e Tecnológico (CNPq)

Cecil, R.; Goldman, L.; Ausiello, D. Cecil Medicine. Philadelphia: Saunders Elsevier. 2008.

${ }^{2}$ Leslie, R.; Catherine, M. Modern management of haemophilic arthropathy. British journal of haematology. 2007, 136(6), 777-787.

${ }^{3}$ Hassan, T.; Badr, M.; El-Gerby, K.; Correlation between musculoskeletal function and radiological joint scores in haemophilia A adolescents. Haemophilia. 2011, 17(6), 920-925.

${ }^{4}$ Hilliard, P; et al. Hemophilia joint health score reliability study. Haemophilia. $2006,518-525$. 